\title{
The Effect of an Education Program on Japanese Nurses' Attitudes toward Foreign Patients
}

\author{
Airi Takashima*, Hiroya Matsuo \\ Department of International Health, Kobe University Graduate School of Health Sciences, Japan
}

Copyright $\bigcirc 2017$ by authors, all rights reserved. Authors agree that this article remains permanently open access under the terms of the Creative Commons Attribution License 4.0 International License

\begin{abstract}
To improve Japanese nurses' ability to take care of foreign patients, we developed an active learning education program and examined whether it had any effect on their nursing skills and attitudes toward foreign patients. Our education program consisted of three sessions, conducted at two general hospitals in Osaka Prefecture. Thirty-nine nurses joined the education program (comprising the education group), while 138 nurses completed the questionnaire (comprising the control group). The questionnaire consisted of questions on demographics, attitudes toward foreign patients, and self-efficacy. For the education group, questionnaires were evaluated at three time points, and for the control group, at two time points. The study demonstrated that both nurses' understanding of and communication with foreign patients were significantly improved after taking the education program. Nurses' anxiety levels regarding foreign patients likewise showed a decrease, and nursing care to foreign patients significantly improved, after taking the education program. On the GSES scale, the "Very high" responses increased in the education group. We concluded that the active learning education program had positive effects on nurses' understanding of and communication with foreign patients as well as the alleviation of nurses' anxiety, thereby enabling nurses to acquire nursing care skills necessary for foreign patient care.
\end{abstract}

Keywords Foreign Patients, Immigrant Patients, Cultural Competency, Transcultural Nursing, Intercultural Education

\section{Introduction}

According to 2015 statistics by the Ministry of Justice of Japan, the number of foreign residents in Japan is about 2 million [1]. As they reside for longer periods in Japan, they encounter various problems in terms of education, social security services, work and home environments, and especially medical treatment [2]. A survey by Japan Hospital Association reported that $78.6 \%$ of hospitals in Japan had treated foreign patients and $75.6 \%$ of those foreign patients were residents of Japan [3].

Several reports have indicated that there are health gaps between foreign and Japanese patients, owing to differences in language, medical system and culture [4, 5, 6]. Hamai indicates that doctors and pharmacists engage in less communication with foreign patients than with Japanese patients [7]. It is suggested that a large number of nurses may be providing insufficient care to foreign patients and may also feel anxiety toward providing care to foreign patients due to differences in language, culture and lifestyle [5.8]. Nevertheless, nurses desire to offer good quality nursing care to foreign patients as well as to Japanese patients [8].It is therefore very important that nurses acquire the ability to take care of foreign patients due to the vital roles they play in such care. However, there are no reports available on on-the-job-training education programs for Japanese nurses for taking care of foreign patients, or the usefulness of such programs.

Thus, we developed the active learning education program to train Japanese nurses to take care of foreign patients and examined whether it affected nurses' attitudes toward foreign patients and improved their nursing skills.

\section{Subjects and Method}

\subsection{Subjects}

This study was conducted at two General Hospitals (Hospital $\mathrm{T}$ and Hospital C) in Osaka Prefecture from November 2011 to March 2013. 177 nurses who had experience of providing nursing care to foreign patients were enrolled in the study. We advertised the education program to the nurses through the head nurses at the hospitals. In the end, 39 nurses out of 177 took the education program (education group), while the remaining 138 nurses only completed the questionnaire and did not take the program (control group). All of the nurses understood the purpose of the study and agreed to participate. 


\subsection{Method}

\subsubsection{Development and Implementation of the Education Program}

In order to develop the education program, we selected several terms from the following Japanese database services within the designated time period-the Japan Medical Abstracts Society Ichushi Web service (1983-2011), Medical Online (1983-2011), CiNii (1983-2011) and PubMed (1983-2011) — using keywords such as "foreign patients," "immigrant patients," "cultural competency," "transcultural nursing," and "intercultural education." Many foreign researches reported the importance of transcultural nursing knowledge for nurses, and several reports dealt with the effects of nursing education programs on the acceptance and awareness of foreign patients. However, there were no reports describing Japanese nursing education programs on the acceptance of foreign patients. From the results obtained, we selected 42 studies and analyzed their aims and methods. Consequently, the following three factors were targeted as issues to be addressed regarding the provision of nursing care to foreign patients: (1) the language barrier; [9-11] (2) the cultural competence of the health care providers; [12-14] and (3) the medical or health insurance system [15-17]. To tackle the above issues, we developed the education program [13, 18-25]. The purpose of the program was to provide nurses with information on providing nursing care to foreign patients, and improve the nurses' self-confidence.

The education program comprised three sessions (Table 1). The first session covered preparation for receiving foreign patients (the patients' backgrounds; anxiety and problems relating to differences in health care systems, culture and customs; considerations regarding nursing care; and problems using interpretation services at a hospital). The second session involved the actual practice of providing nursing care to foreign patients (communicating in easy Japanese, filling out medical histories with mock patients in easy Japanese or the patients' own languages, using multilingual tools, and discussing with foreign patients and participants in Japanese). The third session was a follow-up seminar (including discussion among nurses regarding their provision of nursing care to foreign patients, discussion with foreigners concerning their experiences of Japanese hospital visits, and the planning of nursing care for foreign patients). Each session was held for 90 minutes after the end of the day shift.

The education program was conducted in an active learning style and held over three sessions (two within a four-week period and one follow-up session three months later).

\subsubsection{Evaluation of Education Program}

\subsubsection{Questionnaire}

"Foreign patients" in this study were defined as patients who had difficulty communicating in Japanese. The questionnaire consisted of questions regarding demographics, attitudes toward foreign patients, and self-efficacy. The demographics used included age, nursing career, experience of providing nursing care to foreign patients, experience of staying outside of Japan for more than one month, presence or absence of foreign friends, experience of hearing lectures about the provision of nursing care to foreign patients, and foreign language ability. Foreign language ability was based on a four-point scale (1="None at all"; 2="Greetings only"; $3=$ "Daily conversation"; and $4=$ "Communication on a medical level").

There were three items in the questionnaire regarding the nurses' attitudes toward foreign patients: communication with and understanding of foreign patients; the anxiety level when communicating with foreign patients; and the provision of nursing care to Japanese patients and foreign patients.

The abilities of the nurses to communicate with and understand foreign patients were evaluated in percentages (0-100\%).

The nurses' anxiety levels when providing nursing care to Japanese and foreign patients were evaluated on a four-point scale (1="Almost never"; 4="Almost always"). "Anxiety toward foreign patients" consisted of 10 items : "Preparation for receiving foreign patients into hospital," "Time needed to communicate," "Whether the foreign patients understand what the nurse is saying," "Communicating with foreign patients (in Japanese)," "Medical knowledge and language ability of the foreign patients' interpreters," "Good relationships with foreign patients," "Obtaining foreign patients' medical histories," "Obtaining foreign patients' backgrounds and lifestyles," "Providing nursing care with consideration for foreign patients' cultures and religions," and "The availability of medical support systems for foreign patients."

"Nursing care to patients" consisted of 10 items: "Receiving patients in a reassuring manner," "Visiting patients' bedsides," "Explaining examinations and the reasons for taking them to patients," "Preparing easy-to-understand documents," "Providing nursing care with consideration for patients' cultures and religions," "Evaluating how to improve patients' understanding of their nursing care," "Providing nursing care that patients can trust," "Respecting the will of the patients in deciding their own nursing care," "Providing nursing care with consideration for the anxiety of the patient," and "Explaining how to prevent medical accidents."

\subsubsection{General Self-Efficacy Scale (GSES)}

The Japanese version of the GSES was developed by Sakano and Tojo (1986) to measure the strength of a person's general perceived self-efficacy $[26,27]$. The GSES consists of three categories with 16 items. The three categories are "optimism," "anxiety about failure," and "social position." Each category is further divided into five levels, with less than 3 as "Very low"; 4-7 as "Rather low"; 8-10 as 
"Average"; 11-14 as "Rather high"; and 15 or more as "Very high." Negative answers are scored "0" and positive answers are scored "1"; hence the total scores range from 0 to 16 , with a higher score indicating greater self-efficacy [27].

For the intervention (education) group, we evaluated the data obtained from the self-administered questionnaires at three time points: before the nurses took the education program, after taking the two education sessions, and after the follow-up session. For the control group, we evaluated the data at two time points: before the start of the education program and after the education program.

We asked a head nurse to distribute the questionnaire to the nurses' mailboxes. A collection box was provided at the nursing station.

\subsubsection{Statistical Analysis}

Paired-sample $t$ tests and Pearson's chi-square test were used to compare the first education program and the follow-up program responses across two groups. The level of significance was set at $\mathrm{p}<.05$. All data were statistically analyzed using SPSS (version 14.0) Windows.

\subsubsection{Ethical Considerations}

This study was approved by the Ethical Committees of Kobe University Graduate School of Health Sciences. The subjects were informed that participation in the study was voluntary and that they were free to withdraw at any time.

\section{Demographics}

The mean age of the nurses was $36.0 \pm 9.6$ years (mean \pm SD) for the education group and $31.7 \pm 8.1$ years for the control group. The total length of nursing career was $11.9 \pm$ 8.6 years for the education group and $8.6 \pm 6.7$ years for the control group. $82.1 \%(n=32 / 39)$ of the education group and $77.7 \%(\mathrm{n}=107 / 136)$ of the control group had had experience of providing nursing care to foreign patients within a one year period. Ability in a foreign language was as follows: "None at all" $-46.2 \%(\mathrm{n}=18 / 39)$ for the education group and $48.5 \%(\mathrm{n}=66 / 136)$ for the control education group and $48.5 \%$ $(\mathrm{n}=66 / 136)$ for the control group; "Greetings only" $-51.3 \%$ $(n=20 / 39)$ for the education group and $46.3 \%(n=63 / 136)$ for the control group; "Daily conversation".

\subsection{Changes in Nurses' Attitudes toward Foreign Patients}

\subsubsection{Evaluation of Nurses' Understanding of and} Communication with Foreign Patients before and after the Education Program

In the education group, 'Nurses' understanding of foreign patients" by percentage was $38.5 \pm 17.5 \%, 45.7 \pm 13.3$, and $54.3 \pm 14.0$, respectively, before the education program, after the second session, and after the follow-up. The percentages

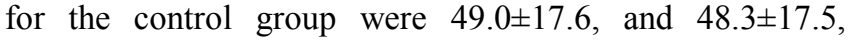
respectively, before the education program and after the follow-up. The percentages for "Nurses' communication with foreign patients" after the education program and after the follow-up were significantly higher than before the education $(\mathrm{P}=0.008)$.

The percentages for 'Nurses' communication with foreign patients" in the education group were $38.5 \pm 17.3,47.4 \pm 13.0$, and $52.0 \pm 12.3$, respectively, before the education program, after the second session, and after the follow-up. The percentages for the control group were $48.5 \pm 17.4$ and $46.9 \pm 14.0$, respectively, before the education program and after the follow-up. The percentages for 'Nurses' communication with foreign patients" after the education program and after the follow-up were significantly higher than before the education program $(\mathrm{P}=0.032)$ (Table 3$)$.

\subsubsection{The Scoring Of "Nurses' Anxiety toward Foreign Patients" before and after the Education Program}

The scores for "Preparation for receiving patients into hospital" and "Communicating with foreign patients (in Japanese)" in the education group were $3.7 \pm 0.1$ and $3.7 \pm 0.1$, respectively, before the education program, and $3.3 \pm 0.1$ and $3.2 \pm 0.1$ respectively, after the follow-up (Table 4). These two anxiety items were significantly lower after the follow-up than before the education program $(\mathrm{P}=0.03$ and $\mathrm{P}$ $=0.03$, respectively).

\subsubsection{Nurses' Practice}

Regarding the scores of "Changes in nursing care provided to foreign patients before the education program and after the follow-up," the scores for "Explaining examinations and the reasons for taking them to patients," "Providing nursing care concerned with foreign patients' culture and religion," "Evaluating how to improve patients' understanding of their nursing care," and "Providing nursing care with consideration for the anxiety of the patient" were $3.2 \pm 0.8,2.4 \pm 0.8,2.9 \pm 0.7$, and $2.8 \pm 0.7$, respectively, before the education program, and $3.6 \pm 0.7,2.8 \pm 0.9,3.4 \pm 0.7$, and $3.2 \pm 0.6$, respectively, after the follow-up, in the education group (Table 5). Four items received significantly higher skills after the follow-up than before the education program $(\mathrm{P}=0.002, \mathrm{P}=0.05, \mathrm{P}=0.008$, and $\mathrm{P}=0.002$, respectively).

Regarding the provision of nursing care to foreign patients and Japanese patients, the scores for nursing care to Japanese patients were higher than those for nursing care to foreign patients before the education program and after the follow-up (Table 6). For "Providing nursing care concerned with foreign patients' culture and religion" the score for nursing care to Japanese patients after the follow-up (3.1 \pm 0.9$)$ was significantly lower than that before the education program (3.4 \pm 0.8$)(\mathrm{P}=0.04)$. 
Table 1. Education program of nursing care to foreign patients: Three sessions

\begin{tabular}{|c|c|c|}
\hline Program & Theme and Activities & Method \\
\hline \multirow{6}{*}{ First session } & Preparation for receiving foreign patients & \\
\hline & Understanding the feelings of foreign patients & Activity \\
\hline & Background of foreign patients & Lecture \\
\hline & Anxiety and problems for foreign patients visiting the hospital & Activity, Lecture \\
\hline & $\begin{array}{l}\text { Considerations regarding nursing care (Transculture of nursing) Foreign patients and medical health care } \\
\text { system in Japan }\end{array}$ & Lecture \\
\hline & How to use interpreters in the hospital & Lecture \\
\hline \multirow{4}{*}{ Second session } & Communication with foreign patients & \\
\hline & How to communicate in easy Japanese & Lecture \\
\hline & $\begin{array}{l}\text { Filling out medical history forms for foreign patients (Language: English, Chinese, Indonesian and either } \\
\text { Portuguese or Spanish) }\end{array}$ & Activity \\
\hline & Discussion with foreigners (For a better understanding of communicating in Japanese ) & Activity, Lecture \\
\hline \multirow{4}{*}{ Follow-up session } & Experience of nursing care to foreign patients & \\
\hline & Discussion among nurses (Experiences of nursing care to foreign patients) & Activity \\
\hline & Hearing experiences of Japanese hospital visits from foreigners & Activity \\
\hline & Nursing plan for foreign patients & Lecture \\
\hline
\end{tabular}

Table 2. Demographics of subjects

\begin{tabular}{|c|c|c|}
\hline & Education group $(\mathrm{N}=39)$ & Control group $(\mathrm{N}=138)$ \\
\hline Age (y) & $36.0 \pm 9.6$ & $31.7 \pm 8.1$ \\
\hline Total length of nursing career $(y)$ & $11.9 \pm 8.6$ & $8.6 \pm 6.7$ \\
\hline \multicolumn{3}{|c|}{ Providing nursing care to foreign patients in one year period } \\
\hline None / 1 to $5 /$ & $7 / 39(17.9 \%) / 28 / 39(71.8 \%)$ & $29 / 136(21.3 \%) / 88 / 136(64.7 \%)$ \\
\hline 6 to $10 / 11$ to $30 /$ & $3 / 39(7.7 \%) / 1 / 39(2.6 \%)$ & $13 / 136(9.6 \%) / 4 / 136(2.9 \%)$ \\
\hline More than 30 & $0 / 39(0 \%)$ & $2 / 136(1.5 \%)$ \\
\hline \multicolumn{3}{|c|}{ Experience staying outside Japan more than one month } \\
\hline Experience & $3 / 39(7.7 \%)$ & $2 / 138(1.4 \%)$ \\
\hline No experience & $36 / 39(92.3 \%)$ & $136 / 138(98.6 \%)$ \\
\hline \multicolumn{3}{|l|}{ Presence or absence of foreign friends } \\
\hline Presence & $4 / 39(10.3 \%)$ & $16 / 138(11.9 \%)$ \\
\hline Absence & $35 / 39(89.7 \%)$ & $118 / 138(88.1 \%)$ \\
\hline \multicolumn{3}{|c|}{ Experience of hearing lectures about the provision of nursing care to foreign patients } \\
\hline Experience & $2 / 39(5.1 \%)$ & $10 / 138(7.2 \%)$ \\
\hline No experience & $37 / 39(94.9 \%)$ & $128 / 138(92.8 \%)$ \\
\hline \multicolumn{3}{|l|}{ Foreign language ability } \\
\hline None at all / Greetings only & $18 / 39(46.2 \%) / 20 / 39(51.3 \%)$ & $66 / 136(48.5 \%) / 63 / 136(46.3 \%)$ \\
\hline Daily conversation & $1 / 39(2.6 \%)$ & $7 / 136(5.2 \%)$ \\
\hline Medical level & $0 / 39(0 \%)$ & $0 / 136(0 \%)$ \\
\hline
\end{tabular}

$-2.6 \%(\mathrm{n}=1 / 39)$ for the education group and $5.2 \%(\mathrm{n}=7 / 136)$ for the control group; and "Communication on a medical level" - none in either group (Table 2). 
Table 3. Communication with and understanding of foreign patients before education and after education

\begin{tabular}{|c|c|c|c|c|c|c|}
\hline Questionnaire & Group & Total (n) & Before & $\begin{array}{c}\text { After second } \\
\text { session }\end{array}$ & $\begin{array}{c}\text { After } \\
\text { follow-up }\end{array}$ & p-value \\
\hline Nurses' understanding of & Education & 23 & $38.5 \pm 17.5$ & $45.7 \pm 13.3$ & $54.3 \pm 14.0$ & $0.008^{* *}$ \\
foreign patients (\%) & Control & 135 & $49.0 \pm 17.6$ & - & $48.3 \pm 17.5$ & 0.67 \\
\hline Nurses communication to with & Education & 23 & $38.5 \pm 17.3$ & $47.4 \pm 13.0$ & $52.0 \pm 12.3$ & $0.032^{*}$ \\
foreign patients (\%) & Control & 135 & $48.5 \pm 17.4$ & - & $46.9 \pm 14.0$ & 0.27 \\
\hline
\end{tabular}

Paired-sample t test; ** Significant $(\mathrm{p}<0.01)$, ${ }^{*}$ Significant $(\mathrm{p}<0.05)$

Table 4. Changes in nurses' anxiety regarding foreign patients before and after educational program

\begin{tabular}{|c|c|c|c|c|c|}
\hline Questionnaire & Group & Total (n) & Before & After follow-up & $\boldsymbol{p}$ - value \\
\hline Preparation for receiving foreign & Education & 27 & $3.7 \pm 0.1$ & $3.3 \pm 0.1$ & $0.003^{* *}$ \\
patients & Control & 138 & $3.3 \pm 0.1$ & $3.5 \pm 0.1$ & 0.241 \\
\hline Communicating with foreign & Education & 27 & $3.7 \pm 0.1$ & $3.2 \pm 0.1$ & $0.003^{* *}$ \\
patients (in Japanese) & Control & 138 & $3.5 \pm 0.1$ & $3.4 \pm 0.0$ & 0.817 \\
\hline
\end{tabular}

Paired-sample $\mathrm{t}$ test; ** Significant $(\mathrm{p}<0.01)$, Significant $(\mathrm{p}<0.05)$

4-Almost Always,3 -Somewhat Frequently, 2-Somewhat Infrequently, 1-Almost Never

Table 5. Changes in nursing care provided to foreign patients before education and after follow-up

\begin{tabular}{|c|c|c|c|c|c|}
\hline Questionnaire & Group & Total (n) & Before & $\begin{array}{c}\text { After } \\
\text { follow-up }\end{array}$ & $p$-value \\
\hline \multirow{2}{*}{ Examination explanations and reasons } & Education & 25 & $3.2 \pm 0.8$ & $3.6 \pm 0.7$ & $0.002^{* *}$ \\
\hline & Control & 132 & $3.2 \pm 1.7$ & $3.4 \pm 0.8$ & 0.17 \\
\hline \multirow{2}{*}{$\begin{array}{l}\text { Providing nursing care concerned with foreign patients' } \\
\text { culture and religion }\end{array}$} & Education & 25 & $2.4 \pm 0.8$ & $2.8 \pm 0.9$ & $0.05^{*}$ \\
\hline & Control & 135 & $2.6 \pm 1.5$ & $2.8 \pm 0.07$ & 0.18 \\
\hline \multirow{2}{*}{$\begin{array}{c}\text { Evaluating how to improve patients' understanding of } \\
\text { their nursing care }\end{array}$} & Education & 25 & $2.9 \pm 0.7$ & $3.4 \pm 0.7$ & $0.008^{* *}$ \\
\hline & Control & 135 & $3.1 \pm 1.3$ & $3.2 \pm 0.8$ & 0.27 \\
\hline \multirow{2}{*}{$\begin{array}{l}\text { Providing nursing care with consideration for the anxiety } \\
\text { of the patient }\end{array}$} & Education & 25 & $2.8 \pm 0.7$ & $3.2 \pm 0.6$ & $0.002^{* *}$ \\
\hline & Control & 135 & $3.1 \pm 1.3$ & $3.2 \pm 0.7$ & 0.45 \\
\hline
\end{tabular}

Paired-sample t test; ** Significant $(\mathrm{p}<0.01),{ }^{*}$ Significant $(\mathrm{p}<0.05)$

4-Almost Always,3 -Somewhat Frequently, 2-Somewhat Infrequently, 1-Almost Never

Table 6. Comparison of nursing care to foreign patients and Japanese patients, before education and in follow-up

\begin{tabular}{|c|c|c|c|c|c|}
\hline Questionnaire & Group & Total (n) & Before & $\begin{array}{c}\text { After } \\
\text { follow-up }\end{array}$ & p-value \\
\hline \multirow{2}{*}{ Examination explanations and reasons } & Foreigner & 25 & $3.2 \pm 0.8$ & $3.6 \pm 0.7$ & $0.002^{* *}$ \\
\hline & Japanese & 27 & $4.0 \pm 0.2$ & $3.9 \pm 0.3$ & 0.57 \\
\hline \multirow{2}{*}{$\begin{array}{l}\text { Providing nursing care concerned with foreign patients' } \\
\text { culture and religion }\end{array}$} & Foreigner & 25 & $2.4 \pm 0.8$ & $2.8 \pm 0.9$ & $0.05^{*}$ \\
\hline & Japanese & 27 & $3.4 \pm 0.8$ & $3.1 \pm 0.9$ & $0.04^{*}$ \\
\hline \multirow{2}{*}{$\begin{array}{l}\text { Evaluating how to improve patients' understanding of } \\
\text { their nursing care }\end{array}$} & Foreigner & 25 & $2.9 \pm 0.7$ & $3.4 \pm 0.7$ & $0.008^{* *}$ \\
\hline & Japanese & 27 & $3.8 \pm 0.4$ & $3.7 \pm 0.5$ & 0.49 \\
\hline \multirow{2}{*}{$\begin{array}{l}\text { Providing nursing care with consideration for the anxiety } \\
\text { of the patient }\end{array}$} & Foreigner & 25 & $2.8 \pm 0.7$ & $3.2 \pm 0.6$ & $0.002^{* *}$ \\
\hline & Japanese & 27 & $3.8 \pm 0.4$ & $3.9 \pm 0.3$ & 0.18 \\
\hline
\end{tabular}

Paired-sample t test; ** Significant $(\mathrm{p}<0.01),{ }^{*}$ Significant $(\mathrm{p}<0.05)$

4-Almost Always, 3 -Somewhat Frequently, 2-Somewhat Infrequently, 1-Almost Never

Table 7. Change of General Self-efficacy Scale of total scoring before education and in follow-up

\begin{tabular}{|c|c|c|c|c|}
\hline Group & Total (n) & Before & After follow-up & $\boldsymbol{p}$-value \\
\hline Education & 26 & $7.5 \pm 4.0$ & $7.3 \pm 4.4$ & 0.77 \\
\hline Control & 137 & $6.7 \pm 8.8$ & $6.5 \pm 7.4$ & 0.87 \\
\hline
\end{tabular}

Paired-sample $\mathrm{t}$ test; ** Significant $(\mathrm{p}<0.01), *$ Significant $(\mathrm{p}<0.05)$

$<3$ very low, $4 \sim 7$ tend to be low, $8 \sim 10$ normal, $11 \sim 14$ tend to be high, $>16$ very high 
Table 8. Distribution of the score of GSES scoring between education and control group

\begin{tabular}{|c|c|c|c|c|c|c|c|}
\hline & very low & $\begin{array}{c}\text { tend to be } \\
\text { low }\end{array}$ & normal & $\begin{array}{c}\text { tend to be } \\
\text { high }\end{array}$ & very high & $\begin{array}{c}\text { Pearson's } \\
\text { chi-square test }\end{array}$ & $p$-value \\
\hline \multicolumn{8}{|l|}{ Before education } \\
\hline Education group & 8 & 12 & 10 & 9 & 0 & & \\
\hline Control group & 45 & 39 & 32 & 20 & 0 & 3.0 & 0.4 \\
\hline \multicolumn{8}{|l|}{ After education } \\
\hline Education group & 5 & 8 & 6 & 4 & 3 & & \\
\hline
\end{tabular}

Pearson's chi-square test, $* *$ Significant $(\mathrm{p}<0.01)$, Significant $(\mathrm{p}<0.05)$

$<3$ very low, $4 \sim 7$ tend to be low, $8 \sim 10$ normal, $11 \sim 14$ tend to be high, $>16$ very high

\subsection{General Self-Efficacy Scale (GSES)}

Regarding the GSES, the total scores for the education group were $7.5 \pm 4.0$ and $7.3 \pm 4.4$, respectively, before the education program and after the follow-up. In the total score of general self-efficacy, there were no significant differences. (Table 7)

Before the education program, the distribution of GSES scoring between the education and the control group showed no significant differences. In the comparison between the education and control groups after the follow-up session, the score for the education group, $11.7 \quad(\mathrm{P}=0.02)$, was significantly different from the control group. (Table 8 )

\section{Discussion}

We developed an active learning education program for the provision of nursing care to foreign patients. We were able to demonstrate for the first time the positive effects of the active learning education program on the understanding of and communication with foreign patients, the alleviation of nurses' anxiety, and the acquisition of nursing care skills among nurses.

In this study, there is a limitation of the number of participants in the education group due to the difficulty of attending the education program during the Japanese nursing work schedules. The mean age of nurses in the education group was higher than that in the control group. The mean total length of nursing career in the education group was also longer than that of the control group. This may have been due to the difficulty for younger nurses to participate in the education program, as it was held after the day shift. However, there were no differences in other demographic items such as experience of providing nursing care to foreign patients, length of time outside Japan, attendance at lectures on nursing care to foreign patients, having foreign friends, and foreign language skills, between the education group and the control group. This indicates that the two groups may have had similar levels of transcultural experience.

Regarding the effect of the education program, in terms of nurses' communication with foreign patients, the education group's score was initially lower than that of the control group. After the follow-up program, the mean percentage of the education group exceeded that of the control group.

Regarding changes in nurses' anxiety regarding foreign patients before and after the education program, the scores for "Preparation for receiving foreign patients into hospital" and "Communication with foreign patients (in Japanese)" significantly decreased in the education group after the follow-up. In our education program, nurses learned and practiced how to speak easily in understandable Japanese with foreign mock patients. Hasegawa reports that, regarding factors contributing to Japanese nurses' anxiety toward foreign patients, language was ranked first, followed by cultural differences, differences in lifestyle and customs, and differences in ways of thinking about diseases. Additionally, nurses who had experience of providing nursing care to foreign patients had less anxiety than nurses without such experience [8]. Taking this report together with our findings, it can be shown that the experience of communicating with foreign patients improved nurses' confidence in communicating professionally with foreign patients. Improved confidence in turn resulted in awareness of the possibility of better mutual understanding through communication in easy Japanese.

We coordinated the evaluation of nurses' care for foreign patients in our study based on Hamai's report on care for patients by doctors and pharmacists [7]. The education program improved the provision of nursing care to foreign patients in terms of "Explaining examinations to patients and the reasons for taking them," "Providing nursing care concerned with foreign patients' culture and religion" "Evaluating how to improve patients' understanding of their nursing care," and "Providing nursing care with consideration for the anxiety of the patient." These results correspond with Hamai's finding that doctors and pharmacists engaged in less communication with foreign patients than with Japanese patients [7]. Regarding the same items, comparing the provision of nursing care to foreign and Japanese patients, "Providing nursing care concerned with foreign patients' culture and religion" was the only item that received significantly lower scores after the follow-up than before the education. This was due to the nurses' increased awareness, after taking the education program, of their lack of cultural understanding relating to nursing care even with regard to Japanese patients. Wynia reports that, in the United 
States, health outcomes are strongly influenced by how well health care professionals communicate with individual patients and patient communities about disease prevention, symptoms, treatment plans and options, risks and benefits, medication instructions, and other relevant topics [28]. While Japan lacks a significant transcultural background, communication between nurses and patients is equally relevant. In this study, our active learning style education program had a positive effect on the provision of nursing care to foreign patients, due to the improvement of communication with foreign patients.

We measured the nurses' General Self-Efficacy Scale (GSES) with respect to foreign patients. The GSES has been used to evaluate important aspects of human motivation and behavior, as well as influences on actions that affect one's life. Nonaka reports that an improvement in nurse's self-efficacy is directly related to the development of better relationships between foreign patients and nurses in Japan [29]. According to Kayano, the mean total GSES score among nurses is lower than that of the general Japanese female population [30]. The score in the education group in our study was same as that reported by Kayano, while the score in the control group was lower than that reported by Kayano. Comparing the GSES scale before and after the education program, an increase in the rate of "Very high" responses was observed in the education group. It is suggested that nurses rated themselves as having low self-efficacy in terms of providing nursing care to foreign patients, and taking the education program may have improved their self-efficacy.

Japan, as a geographically and historically isolated country, can be assumed to have a low basic level of transcultural readiness. An awareness of transcultural understanding is immediately necessary for nurses in the hospitals in order to respond to the needs of the growing international community in Japan.

\section{Conclusions}

In conclusion, we demonstrated the positive effects of the active learning education program on nurses' understanding of and communication with foreign patients, the alleviation of nurses' anxiety, and nurses' acquisition of nursing care skills. As the number of foreign residents increases, and with the Olympic Games being held in Japan in 2020, there will be increased necessity to provide quality nursing care to foreign patients. We believe that our education program will serve as a valuable and necessary resource for hospitals in order to reach this goal.

\section{Acknowledgements}

The authors thank the participants and all who cooperated with this study.

\section{REFERENCES}

[1] The Ministry of Justice of Japan, The number of foreign residents in Japan, 2016, online available fromhttp://www.moj.go.jp/nyuukokukanri/kouhou/nyuukoku kanri04_00057.html, (In Japanese); 2016.

[2] Kobayashi Y. Ishi iryousha kannkei no tameno gaikokujin shinryou gaidobukku [Foreign patient medical examination guidebook for doctors and medical workers], Nagai shoten, (In Japanese); 2006.

[3] Nihon Byouin Kyoukai Kokusai Iryou Suishin Iinkai [Japan Hospital Association, International Medical Promotion Committee]. Heisei 27 nenndo iryou no kokusai senkai ni kansuru genjyouketsukka houkokusyo batusui [Heisei year 27 (2015) current situation survey results of a report on the international expansion of medical care], Online availablefromhttps://www.hospital.or.jp/pdf/06_20151028_0 1.pdf, (In Japanese); 2016.

[4] Ministry of Health, Labor, and Welfare of Japan. Specified Report of Vital Statistics in 2014: Demographic statistics including foreign nationals, Online available from http://www.mhlw.go.jp/toukei/saikin/hw/jinkou/tokusyu/gai koku14/dl/gaikyo.pdf (In Japanese); 2016.

[5] Maeno M., Sakuyama M., Motoyama S., Matsuo H. Japanese Nurses' Views of Perioperative Management of Foreign Patients in Osaka, Kokusai Hoken Iryo [Journal of International Health], 6 (4), 273-280; 2011.

[6] Hayashi M, Mori Y. A Study on Medical and Nursing care Need for Foreign Patient Women, Gunma Hokengaku kiyou [Gunma university health studies bulletin], 23.101-108, (In Japanese) ; 2002.

[7] Hamai T. Questionnaire study of corroborative study on communication gaps among foreign patients and medical service providers in Japan (media report), Heisei 21-23 nendo nihongakujutu shinkoukai kagakukenkyuuhi hojyokinn [Study Result Report of Heisei 21-23 year (2009-2011) Japan Society for the Promotion of Science, Grants-in-Aid for Scientific Research, -media report], (In Japanese) ; 2010.

[8] Hasegawa T., Takegawa C., Tsukida K., Shirakawa K. A study of nursing care for foreigners in Japan. Journal of Fukui Medical University, 3(1.2) 49-55, (In Japanese); 2002.

[9] The Joint Commission. Advancing Effective Communication, Cultural Competence, and Patient- and Family-Centered Care: A Roadmap for Hospitals; 2010. Online available fromhttp://www.jointcommission.org/assets/1/6/ARoadmapf orHospitalsfinalversion727.pdf

[10] Hudelson P, Vilpert S. Overcoming language barriers with foreign-language speaking patients: a survey to investigate intra-hospital variation in attitudes and practices, BMC Health Services Research, Online available fromhttp://bmchealthservres.biomedcentral.com/articles/10.1 186/1472-6963-9-187; 2009.

[11] Iori I. A comprehensive study toward the realization of a universal communication society based on the concept of yasahi i-nihongo (easy Japanese), Hitotsubashi University Repository, Online available fromhttps://hermes-ir.lib.hit-u.ac.jp/rs/bitstream/10086/1932 
0/1/0411100201.pdf, (In Japanese); 2011.

[12] Kawabata F, Ueda R. Knowledge of Nursing for Cultural Diversity-From Child Health Nursing Perspective, Journal of Okinawa Prefectural College of Nursing, 3, 128-134, (In Japanese); 2002.

[13] Giger JN, Davidhizar R. Transcultural Nursing: Assessment and Intervention, fifth edition. Mosby Elsevier, USA; 2007.

[14] Carey R. Cultural Competence Assessment of Baccalaureate Nursing Students: An Integrative Review of the Literature, International Journal of Humanities and Social Science, 1(9), $258-266 ; 2011$.

[15] Nagasaka K, Dodo M. Issues in the Medicine Found in Narratives of Foreign Residents in Yamanashi, Yamanashi Prefectural University bulletin,13, 47-60, (In Japanese) ; 2011.

[16] Kawada F, Ueda R. Knowledge of Nursing for Cultural Diversity: From Child Health Nursing Perspective, Journal of Okinawa Prefectural College of Nursing 3, 128-134, (In Japanese); 2002.

[17] Turuoka S. The characteristics of bilateral cultural dilemmas that foreign mothers in Japan have during the their pregnancy, child birth and raising, Journal of Chiba Academy of Nursing Science, 14(1), 115-123, (In Japanese) ; 2008.

[18] Jogahana H, Fujihara S, Nakashima K, lnoue Y. Study on the Nursing Care Support Based on the Cultural Care Theory by Madelein M. Leininger, Journal of Geosciences Osaka City University,4(3), 11-19, (In Japanese) ; 2008.

[19] [19] Gaikokujinn iryou kanfarensu hen, [Foreigner medical conference]. Iryoujyujisya ga shittuteokitai gaikokujin kanja eno settushikata,[Knowledge of foreign patients for medical workers], Center for Multicultural Society Kyoto, (In Japanese) ; 2011.

[20] MEDINT Kangobukai, [MEDINT Nursing Division]. Gaikokujinn iyou to kango kyouiku, [Education for nursing care for foreigners] Irryou tuuyaku kennkyuukai (MEDINT) shinpojium 2011, Symposium of MEDINT 2011, (In Japanese); 2011.
[21] Munoz C, DoBroka C, Mohammad S. Development of a Multidisciplinary Course in Cultural Competence for Nursing and Human Service Professions, Journal of Nursing Education, 48(9), 495-503; 2009.

[22] Waite R, Calamaro C. A Systemic Challenge to Nursing Education, Knowledge Exchange, and the Knowledge Development Process, Perspectives in Psychiatric Care. 46(1), 74-80; 2010.

[23] Vydelingum V. Nurses' experiences of caring for South Asian minority ethnic patients in a general hospital in England, Nursing Inquiry, 13(1), 23-32; 2006.

[24] Bernal P, Saul N. Communicating with Latino Patients, Journal of Nursing Education, 48(9), 515-518; 2009.

[25] Maier-Lorentz M. Transcultural nursing: its importance in nursing practice. Journal of Cultural Diversity, (15)1,37-43; 2008 .

[26] Sakano Y, Tohjoh M. The General Self-Efficacy Scale (GSES): Scale development and validation. Japanese Journal of Behavior Therapy, 12, 73-82, (In Japanese) ; (1986)

[27] Sakano Y. Verification of validity of General Self-Efficacy Scale (GSES). Waseda Journal of Human Science, 2, 91-98, (In Japanese); 1989.

[28] Wynia M, Matiasek J. Promising practices for patient-centered communication with vulnerable populations: Examples from eight

hospitals, The Commonwealth Fund, Online available from http://www.geneticcounselingtoolkit.com/pdf files/promisin gpracticespatientcenteredcommunication.pdf; 2006.

[29] Nonaka C, Higuchi M, The process of building relationships between foreign patients and nurses in Japan, Kokusai Hoken Iryo (Journal of International Health), 25 (1 ), 21-32. (In Japanese); 2010.

[30] [30] Kayano, Y. The characteristics and related factors of self-efficacy in nurses. Journal of St. Luke's Society for Nursing Research. 3(1), 78-84. (In Japanese); 1999. 